\title{
openheart Physiology-guided myocardial revascularisation in complex multivessel coronary artery disease: beyond the 2014 ESC/EACTS guidelines on myocardial revascularisation
}

\author{
Jan J Piek, ${ }^{1}$ Bimmer E Claessen, ${ }^{1}$ Justin E Davies, ${ }^{2}$ Javier Escaned ${ }^{3}$
}

To cite: Piek JJ, Claessen BE, Davies JE, et al. Physiologyguided myocardial revascularisation in complex multivessel coronary artery disease: beyond the 2014 ESC/EACTS guidelines on myocardial revascularisation. Open Heart 2015;2: 0000308 doi:10.1136/openhrt-2015000308

Received 29 June 2015 Revised 25 August 2015 Accepted 1 September 2015

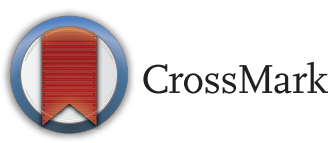

${ }^{1}$ AMC Heart Center, Academic Medical Center, University of Amsterdam, Amsterdam, The Netherlands

${ }^{2}$ International Centre for Circulatory Health, National Heart and Lung Institute, Imperial College London and Imperial College Healthcare NHS Trust, London, UK ${ }^{3}$ Hospital Clinico San Carlos and Faculty of Medicine, Complutense University of Madrid, Madrid, Spain

Correspondence to Professor Jan J Piek; j.j.piek@amc.uva.nl

\section{ABSTRACT}

For patients with multivessel coronary artery disease there are two options for revascularisation: Percutaneous coronary intervention (PCl) or Coronary Artery Bypass Graft Surgery (CABG). In daily clinical practice, a heart team consisting of an interventional cardiologist and a cardiothoracic surgeon decide on the most appropriate mode of revascularization. The current European guidelines on myocardial revascularisation include updated recommendations for patients with multivessel coronary artery disease. In patients with stable angina, three-vessel disease and a SYNTAX score of 23-32 or $>32$ a class I level of evidence $A$ recommendation for $C A B G$ was issued as compared to $\mathrm{PCI}$ which received a class III recommendation. Although the authors of this viewpoint greatly appreciate the efforts of the guideline committee, we believe that it was an oversight not to include recommendations on physiology-guided $\mathrm{PCI}$ in multivessel disease (MVD). In this viewpoint, it is argued that physiology-guided revascularization using current-generation drug-eluting stents is a reasonable alternative for complex multivessel disease.

The 2014 guidelines on myocardial revascularisation of the European Society of Cardiology (ESC) and the European Association for Cardiothoracic Surgery (EACTS) were presented at the ESC meeting in Barcelona. ${ }^{1}$ The authors of this viewpoint are very appreciative of the work performed by the Task Force in producing this document that has enormous relevance both for clinicians and patients. However, the validity of the guideline recommendations seems questionable for the type of revascularisation, that is, coronary artery bypass graft surgery (CABG) or percutaneous coronary intervention $(\mathrm{PCI})$, in patients with stable angina, three-vessel disease and a SYNTAX score of 23-32 or $>32$. A class I level of evidence A recommendation for $\mathrm{CABG}$ was issued as compared to PCI which received a class III recommendation.

First, a level of evidence A which was issued for $\mathrm{CABG}$ in this recommendation is debatable. The references provided by the task force to support it refer to the SYNTAX ${ }^{3}$ and FREEDOM ${ }^{4}$ trials. However, only the SYNTAX trial found a statistical relationship between intermediate and high SYNTAX risk categories and worse outcome of PCI in patients with multivessel disease (MVD), compared with CABG (the FREEDOM trial was not significant for SYNTAX score and included patients with diabetes only). As this recommendation is based on only one randomised trial, a level of evidence B would have been more appropriate.

Second, the difference in major adverse cardiovascular and cerebral events (MACCE) between patients treated with CABG versus PCI with an intermediate SYNTAX score of 23-32 during the 5-year follow-up of the SYNTAX trial was due to a higher incidence of death, myocardial infarction and repeat revascularisation, and this may in part be explained by the specific type of first generation paclitaxel-eluting stents (PES) used in the SYNTAX trial. $^{2}{ }^{3}$ A patient-pooled meta-analysis of the SPIRIT II, III and IV randomised controlled trials including 4989 patients comparing PCI with first generation PES to next-generation everolimus-eluting stents (EES) showed a $28 \%$ reduction in target lesion revascularisation $(\mathrm{p}=0.004)$, and a $55 \%$ reduction in stent thrombosis ( $p=0.003)$ with EES compared with PES at 3-year clinical follow-up. ${ }^{5}$ This reduction in device-related outcomes resulted in a $35 \%$ reduction of all-cause death and myocardial infarction $(p<0.0001)$ with EES. This reduction in target lesion revascularisation and all- 
A

Target Lesion Revascularization

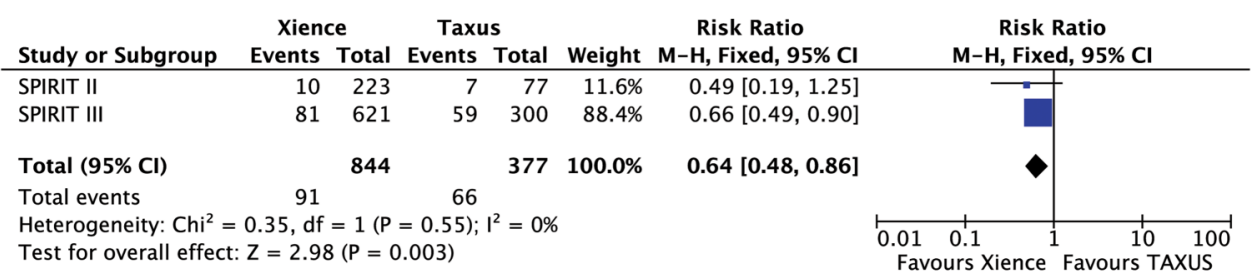

B Death/Myocardial Infarction

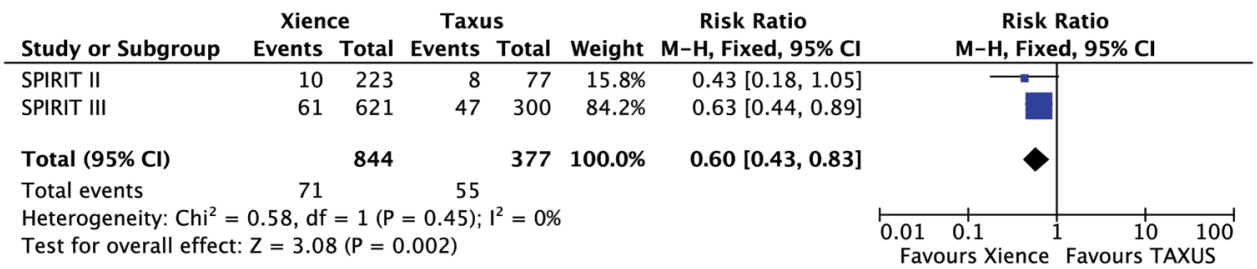

Figure 1 Fixed-effects meta-analysis of five-year outcomes from randomised trials comparing the everolimus-eluting stent (EES) with the paclitaxel-eluting stent (PES). Size of data markers indicates the weight of the study.

cause mortality or myocardial infarction seems to be robust up to 5-year follow-up as illustrated by a fixed-effects meta-analysis of the 5-year results of the SPIRIT II and III trials (figure 1). The SPIRIT IV trial was not included in this meta-analysis as the final follow-up was performed at 3 years. It is obvious that these data can only be extrapolated with caution to the SYNTAX trial cohort, but if we consider a $30 \%$ potential reduction in clinical event rates by using next-generation DES in SYNTAX at 5-year follow-up, there would no longer be any significant differences between the CABG and PCI groups with the lone exception of myocardial infarction in the intermediate SYNTAX score group (figure 2). The recently published BEST (Randomised Comparison of Coronary Artery Bypass Surgery and Everolimus-Eluting Stent Implantation in the Treatment of Patients with Multivessel Coronary Artery Disease) trial yielded similar results. ${ }^{6}$ A total of 880 patients with multivessel coronary artery disease were randomly assigned to PCI with EES or CABG. At a median follow-up of 4.6 years, there were no significant differences in terms of death or myocardial infarction between both groups. There was however an increased rate of repeat revascularisation, due to a significantly higher rate of non-target lesion revascularisation in the PCI group.

In the new guidelines the task force acknowledges 'recent studies have shown the superiority of several newgeneration drug-eluting stents (DES) over earlygeneration DES, not only with respect to efficacy but also safety' (ie, lower restenosis, mortality, myocardial infarction and stent thrombosis rates that dictate individual components of the primary MACCE outcome). ${ }^{1}$ We believe that these considerations should have been taken into account at the time of making the aforementioned recommendation. However, it should be noted that the observed improvement in safety and efficacy outcomes with EES as compared with PES is limited to patients without diabetes mellitus. ${ }^{7}$ The task force also acknowledges that first-generation DES 'currently play an irrelevant role in the treatment of CAD and are largely supplanted by new-generation DES'. ${ }^{1}$ In other words, that early DES technology has been superseded by a

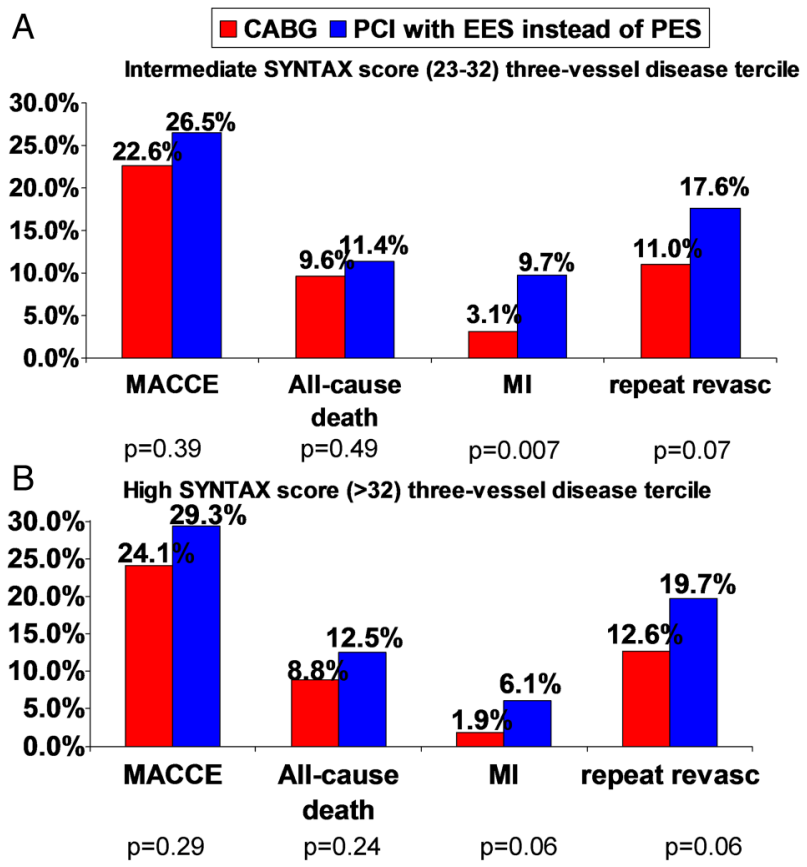

Figure 2 Figures showing the effects of a potential $30 \%$ relative reduction in events with next-generation drug-eluting stents in the percutaneous coronary intervention arm of the SYNTAX three-vessel disease cohorts with intermediate (A) and high SYNTAX scores (B), while assuming an unchanged event rate in the surgical arm (data modified from reference number 3). Pearson $\chi^{2}$ methods were used to recalculate $p$ values. CABG, coronary artery bypass grafting; MACCE, major adverse cerebrocardiovascular events; MI, myocardial infarction; $\mathrm{PCl}$, percutaneous coronary intervention; repeat revasc, repeat revascularisation. 
new generation of safer and more efficacious devices. To be consistent with this statement, we believe that the recommendation based on the SYNTAX trial should be reconsidered.

And third, the SYNTAX and FREEDOM trials utilised angiography-guided revascularisation, while the FAME trials clearly demonstrating the usefulness of fractional flow reserve (FFR)-guided revascularisation in patients with multivessel disease. ${ }^{8}$ In the new guidelines the conclusions of the FAME trials, a randomised multicenter clinical trial aimed to improve revascularisation in patients with multivessel disease, are not clearly linked to the management of this subgroup of patients. An opportunity to deliver the important message that interrogation with FFR of all PCI targets in MVD results in better patient outcome is therefore missed. Interrogation of all target stenoses with FFR is also important because it allows calculation of functional SYNTAX score, that has been shown to be superior to the standard SYNTAX score in terms of risk stratification of patients with multivessel coronary artery disease undergoing PCI. ${ }^{9}$ Currently ongoing studies such as FAME 3, SYNTAX II, IFR-SWEDEHEART and DEFINE-FLAIR are designed to further refine the use of physiological-guided revascularisation based on FFR or instantaneous wave-free ratio (iFR) in the treatment of multivessel coronary artery disease. Ideally, physiological indices using both coronary pressure and flow such as the hyperaemic stenosis resistance index should be used which has been shown to result in increased diagnostic accuracy compared with FFR or coronary flow reserve (CFR) alone. ${ }^{10}$ Since FFR and CFR both have fundamental shortcomings, as previously described in detail. ${ }^{11-13}$ Moreover, assessment of myocardial viability should also be considered in clinical decision-making regarding completeness of revascularisation. It can be argued that revascularisation of stenoses in coronary arteries supplying non-viable myocardium is futile.

On these grounds, we are concerned by the fact that the benefit of next-generation DES over first-generation DES, and the proven superiority of physiological-guided PCI over angiography-guided PCI, are in conflict with the class III recommendation for PCI in complex multivessel disease. We believe that the relevance of this matter warrants reconsideration of this recommendation by the task force.

Contributors BEC wrote the primary draft of the manuscript. JJP, JED and JE reviewed and revised the manuscript.
Competing interests None declared.

Provenance and peer review Not commissioned; externally peer reviewed.

Open Access This is an Open Access article distributed in accordance with the Creative Commons Attribution Non Commercial (CC BY-NC 4.0) license, which permits others to distribute, remix, adapt, build upon this work noncommercially, and license their derivative works on different terms, provided the original work is properly cited and the use is non-commercial. See: http:// creativecommons.org/licenses/by-nc/4.0/

\section{REFERENCES}

1. Windecker S, Kolh P, Alfonso F, et al. 2014 ESC/EACTS Guidelines on myocardial revascularization: the Task Force on Myocardial Revascularization of the European Society of Cardiology (ESC) and the European Association for Cardio-Thoracic Surgery (EACTS) Developed with the special contribution of the European Association of Percutaneous Cardiovascular Interventions (EAPCI). Eur Heart J 2014;35:2541-619.

2. Mohr FW, Morice MC, Kappetein AP, et al. Coronary artery bypass graft surgery versus percutaneous coronary intervention in patients with three-vessel disease and left main coronary disease: 5-year follow-up of the randomised, clinical SYNTAX trial. Lancet 2013;381:629-38.

3. Head SJ, Davierwala PM, Serruys PW, et al. Coronary artery bypass grafting vs. percutaneous coronary intervention for patients with three-vessel disease: final five-year follow-up of the SYNTAX trial. Eur Heart J 2014;35:2821-30.

4. Farkouh ME, Domanski M, Sleeper LA, et al. Strategies for multivessel revascularization in patients with diabetes. $N$ Engl J Med 2012;367:2375-84.

5. Dangas GD, Serruys PW, Kereiakes DJ, et al. Meta-analysis of everolimus-eluting versus paclitaxel-eluting stents in coronary artery disease: final 3-year results of the SPIRIT clinical trials program (clinical evaluation of the Xience $V$ everolimus eluting coronary stent system in the treatment of patients with de novo native coronary artery lesions). JACC Cardiovasc Interv 2013;6:914-22.

6. Park SJ, Ahn JM, Kim YH, et al. Trial of everolimus-eluting stents or bypass surgery for coronary disease. $N$ Engl $J$ Med 2015;372:1204-12.

7. Stone GW, Kedhi E, Kereiakes DJ, et al. Differential clinical responses to everolimus-eluting and paclitaxel-eluting coronary stents in patients with and without diabetes mellitus. Circulation 2011;124:893-900.

8. De Bruyne B, Fearon WF, Pijls NH, et al. Fractional flow reserve-guided $\mathrm{PCl}$ for stable coronary artery disease. $N$ Engl J Med 2014;371:1208-17.

9. Nam CW, Mangiacapra F, Entjes R, et al. Functional SYNTAX score for risk assessment in multivessel coronary artery disease. $J \mathrm{Am}$ Coll Cardiol 2011;58:1211-18.

10. van de Hoef TP, Nolte F, Damman P, et al. Diagnostic accuracy of combined intracoronary pressure and flow velocity information during baseline conditions: adenosine-free assessment of functional coronary lesion severity. Circ Cardiovasc Interv 2012;5:508-14.

11. van de Hoef TP, van Lavieren MA, Henriques JP, et al. Fractional flow reserve-guided percutaneous coronary intervention: does coronary pressure never lie? Curr Treat Options Cardiovasc Med 2014;16:294.

12. Claessen BE, Bax M, Delewi R, et al. The Doppler flow wire in acute myocardial infarction. Heart 2010;96:631-5.

13. van de Hoef TP, Nolte F, Echavarrla-Pinto M, et al. Impact of hyperaemic microvascular resistance on fractional flow reserve measurements in patients with stable coronary artery disease: insights from combined stenosis and microvascular resistance assessment. Heart 2014;100:951-9. 